\section{The effects of retinal and physical orientation, physical size and distance, and intelligence on the perceived "meaning" of stimuli}

\author{
A. LEWIS HILL \\ Institute for Research in Mental Retardation \\ 1050 Forest Hill Rd., Staten Island, N.Y. 10314
}

The perceived meaning of simple stimuli in a $45 \cdot \mathrm{deg}$ conflict situation was examined as a function of two stimulus variables (stimulus size and viewing distance) and two $S$ variables (mental and chronological age). The results indicated that responses are not determined by these variables and that Ss are preset to interpret stimuli according to the physical, rather than the retinal, coordinate system.

The meaning of a visual stimulus often depends on what part of the figure is perceived as the "top" of the figure. The orientation of the stimulus, however, can be defined in terms of either the physical or the retinal coordinate system. Under normal viewing conditions, there is close alignment of these systems, but they can be put into conflict by tilting the S. For instance, if a S's head is tilted 45 deg laterally, a square in physical space is projected as a diamond on the retina. Since these two figures are quite different perceptually, a $S$ 's report of his perception within this conflict situation represents the coordinate system in use. If, under these conditions, a $S$ reports seeing a diamond, he must be using the retinal coordinate system. If he reports seeing a square, he must be using the physical coordinate system.

For normal adult Ss, rotation of the retinal coordinate system does not greatiy influence perception (Rock, 1956; Rock \& Heimer, 1957). For simple stimuli, recognition was easy in a 90-deg conflict situation in which a S lay on his side and viewed a physically upright stimulus. However, if the stimulus was then rotated, without the S's knowledge, so that it was aligned with the retinal coordinate system but tilted within the physical coordinate system, recognition was impaired. Similar results were reported by Attneave \& Olson (1967), who concluded that the perceptual system was preset to make allowances or corrections for head position, on the basis of proprioceptive information.

Walsh \& Wapner (1967) have reported evidence which seems to indicate that the perceptual system is not simply preset to take head position into account, but that stimulus variables, such as the viewing distance to the stimulus, determine which system is employed. In their study, Ss were tilted to a $45 \cdot$ deg angle, with respect to gravity, and were presented with $a+$ or $x$ figure at distances of $8 \mathrm{in}$., $3 \mathrm{ft}$, or $9 \mathrm{ft}$. They reported that the retinal coordinate system was less employed when the distance increased to $3 \mathrm{ft}$. No further differences were found between 3 - and 9-ft presentations. However, they used only one stimulus size and thus confounded retinal size and distance. They also reported a response bias for one of the meanings of the stimulus which was especially prevalent in the 8-in. condition. When the + was aligned with the retinal coordinate system, $70 \%$ of the responses were in terms of the retinal coordinate system. However, when the + was aligned with the physical coordinate system, only $35 \%$ of the responses were in terms of the retinal coordinate system. Thus, one meaning of the figure was given $67.5 \%$ of the time, regardless of whether it was aligned with the retinal or physical coordinate system. By using different $S s$ in each of their conditions, they were unable to obtain any information as to the consistency with which a coordinate system was employed by the Ss.

One purpose of the present study was to investigate the effects of the size of the stimulus and the viewing distance to the stimulus on the consistent use of a coordinate system. If the organism is preset, these variables should make no difference. If, however, the perceptual system is stimulus determined, the retinal coordinate system should be employed more often when the viewing distance is short. If this effect is due to the retinal size of the stimuli, large stimuli should be identified in terms of the retinal coordinate system more often than smaller stimuli at each distance.

A second purpose of this study was to investigate the development of the use of the coordinate systems. According to Wapner \& Werner (1957), children are more egocentric than adults (i.e., stimuli are more likely to be interpreted in terms of the body position). Retardates have also been reported to be more egocentric than normal children of equivalent chronological age (Guyette, Wapner, Werner, \& Davidson, 1964) and should also interpret stimuli more in terms of the retinal coordinate system. SUBJECTS

The retarded Ss were 14 institutionalized male mentally retarded adolescents diagnosed as culturally familial and having no indications of organic impairments. The Ss' IQs ranged from 46 to 67 , with a mean IQ of 52.4. They ranged in age from 17.0 to 19.9 years, with a mean of 18.8 years. The normal children were obtained from a local school. Ten ninth-grade males and 18 second-grade males participated. All Ss demonstrated Snellen acuity of $20 / 29$ or better, with or without correction. No $\mathrm{S}$ demonstrated deviant lateral or vertical phoria.

\section{APPARATUS}

A Bausch and Lomb modified Ortho-Rater was used for the visual screening.

A series of identification figures, consisting of a square, a diamond, $a+$, and an $x$, drawn in ink and centered on $5 \times 8$ in. index cards, were used to insure that Ss could name the stimuli. The square and diamond figures were $2.5 \times 2.5 \mathrm{~cm}$, while the + and $\mathrm{x}$ were composed of $2.5 \mathrm{~cm}$ lines at right angles. The only difference between the square and diamond and between the + and $x$ was the orientation of the figure on the card.

Eight stimulus figures, large and small squares, diamonds, $+s$, and $x s$, were made of luminous tape and mounted on index cards. Solid $75 \times$ $75 \mathrm{~mm}$ squares were used for the large square and large diamond figures, while solid $17 \times 17 \mathrm{~mm}$ squares were used for the small square and small diamond figures. Two luminous lines, $75 \mathrm{~mm}$ long $\times 5 \mathrm{~mm}$ wide, at right angles with centers intersecting, constituted each of the large + and $x$ figures, while the small + and $x$ figures were composed of $17 \times 2 \mathrm{~mm}$ lines. As with the identification figures, orientation distinguished between square and diamond and between + and $x$.

The S's head was held at a 45-deg angle to the left of vertical by a headpiece at one end of a $183 \times 61 \times$ $61 \mathrm{~cm}$ display unit. In this position, the $S$ could view the inside of the unit through two slits, one for each eye, in the end of the unit. A chair was placed next to the unit for $S$ to support himself while standing in this position. PROCEDURE

All testing was on an individual basis. Ss were first visually screened for far-point acuity, lateral phoria, and vertical phoria, as well as for 
Table 1

Percentage of Consistent Responses in Terms of the Physical Coordinate System

\begin{tabular}{lrrrr}
\hline & \multicolumn{3}{c}{ Viewing Distance } \\
\cline { 2 - 4 } & \multicolumn{2}{c}{$20.3 \mathrm{~cm}$} & \multicolumn{2}{c}{$91.4 \mathrm{~cm}$} \\
\cline { 2 - 4 } & \multicolumn{2}{c}{ Stimulus Size } & \multicolumn{2}{c}{ Stimulus Size } \\
\cline { 2 - 5 } & Small & Large & Small & Large \\
Retardates & 81 & 78 & 93 & 89 \\
Second Graders & 91 & 100 & 91 & 92 \\
Ninth Graders & 80 & 87 & 88 & 89 \\
\hline
\end{tabular}

near-point acuity. They were then shown the identification figures under normal viewing conditions, i.e., physical and retinal coordinates systems aligned. They were asked to name each figure to insure that they could differentiate the figures and respond rapidly and consistently to each. Response idiosyncrasies were accepted if used consistently. Thus, responses of "triangle" to the diamond figure, "box" to the square figure, or "cross" to the + figure were accepted. $S$ was brought to the display unit and instructed that he was to look through the holes in the end, supporting himself on the chair. $E$ helped to position S's head at $45 \mathrm{deg}$ left of vertical. The $\mathbf{S}$ was told that when the room lights went out, he would see the figures which had been previously shown to him and that he was to name them as quickly as possible. The room lights were turned off, and all the stimuli were presented once in a random order at eye level at one distance. The room lights were turned on for $2 \mathrm{~min}$ to record the responses and to recharge the luminous stimuli. The experiment was then repeated at the second distance. Half the Ss saw the figures at $20.3 \mathrm{~cm}$ and then at $91.4 \mathrm{~cm}$, while the other half had the opposite presentation order of distances to the figures.

\section{RESULTS}

A consistency measure, defined as responding in the same coordinate system for the two figures of the same shape and size at one distance, was used to eliminate response biases. Thus, if a S responded " $x$ " to a small stimulus at $20.3 \mathrm{~cm}$ which was a + retinally and also responded " $x$ " to a small stimulus at $20.3 \mathrm{~cm}$ which was an $\mathrm{x}$ retinally, both responses were eliminated on the basis of a response bias for $x$ indicated by the inconsistency. The responses of four retardates and one second-grade nonretardate, expressing a response bias for "plus" and "square" in all conditions, and one second-grade nonretardate, expressing a bias for " $x$ " and "square" in all conditions, were eliminated on this basis.

As seen in Table 1, the vast majority of consistent responses are in terms of the physical coordinate system within all conditions.

An analysis of variance with repeated measures on the remaining consistent responses indicated that there were no differences between groups $(F=.734)$ or distance $(F=.489)$. The Group by Distance interaction was also insignificant $(\mathrm{F}=.846)$

Within each group, one or two Ss were responsible for all the retinal coordinate responses. However, they were not always consistent between viewing distances. For example, all of the consistent retinal coordinate system responses within the group of second graders were given by two Ss. One $S$ gave consistent retinal viewing distance but consistent physical coordinate responses at the $91.4-\mathrm{cm}$ viewing distance. Another $\mathrm{S}$ gave consistent retinal coordinate system responses at the $91.4-\mathrm{cm}$ viewing distance but consistent physical coordinate system responses at the $20.3-\mathrm{cm}$ viewing distance; thus, within a viewing distance, all his consistent responses were in terms of the same coordinate system.

$$
\text { DISCUSSION }
$$

Contrary to the findings of Walsh \& Wapner (1967), no differences were found as a function of the presentation distance. When response coordinate responses at the $20.3-\mathrm{cm}$ biases were eliminated, the overwhelming proportion of responses were in terms of the physical coordinate system rather than the retinal coordinate system. The fact that this occurred at both distances and for both large and small stimuli suggests that these stimulus attributes contribute little, if at all, to the perception of simple figures within a 45-deg conflict situation.

No differences were found among the groups, suggesting that, within the age range tested, no developmental function exists, and that intelligence is not a factor.

The overall findings agree with the theory (Attneave \& Olson, 1967) that Ss are preset to respond in terms of the physical coordinate system by correcting for head position, on the basis of proprioceptive information. Further evidence for this position is obtained in the examination of the individual responses. Within a condition, Ss were consistent in their employment of a coordinate system. These Ss appear to have been preset to respond and continued to respond consistently within a condition. Ss also seem to be able to change from the use of one system to the other. However, once the $S$ sets himself to the use of one system, he maintains this set for the remainder of the condition.

\section{REFERENCES}

ATTNEAVE, F. \& OLSON, R. K. Discriminability of stimuli varying in physical and retinal orientation. Journal of Experimental Psychology, 1967, 74, 149-157.

GUYETTE, A., WAPNER, S., WERNER. H. \& DAVIDSON. J. Some aspects of space perception in mental retardates. American Journal of Mental Deficiency. 1964, 69, 90-100.

ROCK. I. The orientation of forms on the retina and in the environment. American Journal of Psychology, 1956, 69, 513-528.

ROCK, I.. \& HEIMER, W. The effect of retinal and phenomenal orientation on the perception of form. American Journal of Psychology, 1957, 70, 493-511.

WALSH, C., \& WAPNER, S. Dependency of "meaning" on physical arrangement between self and stimulus. Paper presented at Eastern Psychological Association meetings, Boston, 1967.

WAPNER, S., \& WERNER, H. Perceptual development: An investigation within the framework of sensory-tonic field theory. Worcester: Clark University Press, 1957. 